\title{
The Relationship between Sleep Habits and Mental Health in Iranian Elementary School Children
}

Farshid Shamsaei ${ }^{1}$

Mohammad Mahdi Daraei ${ }^{2}$

Hassan Aahmadinia ${ }^{3}$

Arash khalili ${ }^{4}$

Marzieh Seif ${ }^{5}$

${ }^{1}$ Associate Professor, Mother and Child Care Research Center, Hamadan University of Medical sciences, Hamadan, Iran.

${ }^{2}$ MSc of Pediatric Student, Faculty of Nursing and Midwifery, Hamadan University of Medical Sciences, Hamadan, Iran.

${ }^{3}$ Department of Biostatistics, Hamadan University of Medical Sciences,

Hamadan, Iran.

${ }^{4}$ Chronic Disease (home care) Research Center, Hamadan university of Medical Sciences, Hamadan, Iran.

${ }^{5}$ MSc of Pediatric Student, Faculty of Nursing and Midwifery, Hamadan University of Medical Sciences, Hamadan, Iran.

\section{Corresponding author:}

Arash khalili.

E-mail: arash5920@yahoo.com

Received: december 14, 2018; Accepted: april 23, 2019.

\begin{abstract}
Objectives: Sleep is one of the basic elements which affects the growth and development and mental health of the child. The aim of this study was to determine the relationship between sleep habits and mental health in elementary school children in Nahavand/Iran. Methods: In this correlation study, 240 children aged 6-11 years old were selected by cluster random sampling from schools of Nahavand city in Iran, 2017. Data were collected through questionnaires included demographic information, children's sleep habits (CSHQ) and children sickness indications (CSI-4). Questionnaires were completed by one of parents as self-report. The data were analyzed using Pearson's correlation and regression analysis. Results: Based on results, Trouble in sleeping was reported by $36 \%$ and mental health disorders by $24.5 \%$ of elementary schools children. The regression analysis showed sleep habits had significant associations with the mental health score. In other words, improper sleep habits were associated with higher scores of illness symptoms of mental health that are indicative of poor mental health. Discussion: Sleep disorder is one of the problems of elementary schools children, which related to their mental health. Sleep health training for parents and trainers in schools can help to improve the mental health of children by reforming proper sleep habits.
\end{abstract}

Keywords: Sleep Habits, Mental Health, Children. 


\section{INTRODUCTION}

Sleep is one of the elementary needs for human survival and health, which is very important in childhood ${ }^{1}$. Sleep has an important impact on rehabilitation, improvement and storage of energy for metabolism, mental operation, neural maturity, learning skills and memory ${ }^{2}$. The disease control center recommends 9-10 hours of sleep for teenagers and more than 10 hours of sleep for school age children ${ }^{1}$. The National Sleep Foundation of America also recommends 8-10 hours for teenagers and 9-11 hours of sleep for school age children ${ }^{3}$. Sleep health is a multidimensional pattern of sleep-wakefulness, adapted to individual, social, and environmental demands, that promotes physical and mental well-being. Good sleep health is characterized by subjective satisfaction, appropriate timing, adequate duration, high efficiency, and sustained alertness during waking hours ${ }^{4}$.

In adolescents and children, disrupted sleep can lead to poor school performance and behavior problems $s^{5}$. However, not observing sleep health is widespread among children, and according to reports in 2015, 43\% of Elementary school students and $29 \%$ of middle school students in America suffer from sleep disorders which the causes are rooted in sleep bad habits ${ }^{3}$. Poor sleep habits and behavior makes many problems in children, so that short-term changes in biological indicators and hormonal activity, followed by overweight or obesity and diabetes, are reported in children with sleep problems more than other children ${ }^{5,6}$.

Training sleep health in childhood can be effective in improving sleep habits by reforming inappropriate behaviors and providing proper sleep pattern ${ }^{7}$. In general, people follow the unique behavior habits and patterns to sleep that the basic foundations of learning these habits are shaped in childhood with regard to cultural and family backgrounds, and the person tries to maintain it throughout life 5 . In addition to the significant effects of proper habits on the physical health of children those are also related to people mental health status?

Kaneita and colleagues also performed a research in Japan in 2007, which showed that mental health is in relation to the status of teenagers' sleep ${ }^{8}$. Paying attention to the mental health of children decreases the risk of mental illnesses and helps to improve health and the quality of life'. Studies have specified that inappropriate sleep habits, such as short sleep or sleeping late are accompanied with mental health problems, include depression, anxiety, decrease in positive feelings, and quasi-psychotic experiences. Also, sleep disorders have a positive relationship with behaviors of suicide and self-harm in teenag$\mathrm{ers}^{7,10}$. Another sleep problems include low attention, reduction in memory capacity, behavioral problems, such as irritability, emotional instability, problematic behaviors, mental illnesses, hyperactivity and poor educational performance ${ }^{6}$.

Since essential foundations for the inappropriate sleep habits and prevention of stable disturbances resulting from it are shaped in childhood, it is very important to search, identify and prevent the shaping of poor sleep habits during this period $^{1}$. Sleep is an important factor in the physical and mental health of children and improves their school performance ${ }^{2,5}$, the study of children's sleep habits and their mental health helps to on time identification of problems and can improve children health through proper interventions. Regarding that most studies in Iran have only studied sleep habits of students and their relationship with children mental health has not been consid$\operatorname{ered}^{1,5}$. Therefore, the aim of this study was to determine the relationship between sleep habits and mental health in Iranian elementary schools children.

\section{MATERIALS AND METHODS}

In this correlation study aimed at specifying the relationship between sleep habits and mental health in elementary students, 240 students were randomly selected from schools of Nahavand, west of Iran in 2017. For sampling, the city of Nahavand was divided into two east and west geographic regions. Two elementary schools and grades 1 to 6 from each school and 10 students from each class were selected randomly.

The sample size was calculated based on the similar study $^{12}$ at the error level of 0.05 at the statistical power of 0.85 and the correlation coefficient of -0.19 .

$$
n=\frac{\left(Z_{1-\frac{a}{2}}+Z_{1-\beta}\right)^{2}}{0.5 \ln \left(\frac{1+r}{1-r}\right)}+3
$$

\section{Instruments}

A) Demographic information questionnaire: Child's information includes: age, gender, birth rank, grade, psychiatric disorders, use of psychiatric drugs and parent information including father's job, mother's job, father's education, mother's education, father and mother's marital status and having mental disorders.

B) The Children's Sleep Habits Questionnaire (CSHQ): This questionnaire was made by Owens et al. in 2000 to screen sleep habits of children between the ages of 3 and $12^{11}$. The questionnaire was consisted of 44 sentences in 5 areas (sleep time, sleep behavior, night awakening, morning awakening and sleepiness). The questions were as 3-point Likert as repeating behavior 0-1 times a week, rarely option (score 1), 2-4 times a week, sometimes option ( score 2), 5-7 times per week, usually options ( score 3), the range of won points is 44 to 132 , respectively. The higher scores obtained from this questionnaire mean that the child has more improper habits ${ }^{5,10}$. The CSHQ showed adequate internal consistency for both the community sample $(0.68)$ and the clinical sample $(0.78)^{11}$. In this study, a Persian version of the questionnaire was used ${ }^{12}$.

C) Child symptom inventories (CSI-4): This questionnaire is a scale of behavior ranking to screen behavior and emotional disorders in children aged between 5 and 12 years old. The fourth edition of the questionnaire DSIM-IV was revised in 1994 with low changes by Gadow and Sprafkin ${ }^{13}$. The questionnaire consists of two forms of parents and teacher's report. Since the parents' form is more sensitive than the teacher's form according to the psychometric evaluation, this form was used in the present study.

This form contains 97 questions to screen 18 behavioral and emotional disorders and includes 11 tables that are named from A to K (Attention Deficit/ hyper activity disorder oppositional defiant disorder, conduct disorder, generalized anxiety

Sleep Sci. 2019;12(2):94-99 
disorder, Anxiety and tic disorders, Psychiatric disorders, mood disorders, pervasive developmental disorders, social phobia, separation anxiety disorder and elimination disorders). Questions are ranked in a 4-point Likert scale (never $=0$, sometimes $=1$, often $=2$, most often $=3$ ), and the score of severity is obtained from the sum of scores of each question ${ }^{14}$. The higher scores related to poor mental health.

Data collection method: all children' parents were invited to participate in study and the criteria of inclusion and exclusion was applied using the information filled in Demographic information questionnaire and the Child symptom inventories. The inclusion criteria included, as children of elementary schools (girls' school and boys' school) of two east and west geographic regions of Nahavand, studying on the grades 1 to 6 . Among them, were excluded those that were using psychiatric drug and not living with parents or exited the study for others reason, such as relocation, death and so on; and for parents, those that suffer of mental illness, don't have at least reading and writing literacy and not completed the questionnaire.

\section{Statistical analysis}

The frequency tables were used to describe the collected data and Pearson correlation coefficient and regression analysis were used with SPSS version 16 software for data statistical analysis and process.

\section{Ethical Consideration}

The Hamadan University of Medical sciences Ethics Committee approved that study (IR.UMSHA.REC.1395.524). Written informed consent was obtained from the parents' subjects. It is also noteworthy that the results of the study were anonymously reported to comply with the ethical criteria Consent for publication.

\section{RESULTS}

The results showed that the most children (32.9\%) were in the age group of 10-11 years old. 52.9\% were the first child and were selected equally in terms of the sex. Most of the children's fathers $(53.3 \%)$ had a sub diploma education and selfemployed (53.8\%). The majority of mothers $(67.1 \%)$ were sub diploma and $95 \%$ were housewife.

The results of the study showed that the mean and standard deviation of students' sleep habits were $64.72 \pm 9.33$. The highest mean related to sleep behavior was $26.87 \pm 4.75$ and the lowest mean for night awakening, was $4.35 \pm 1.48$ in the children. In other words, the high mean means there is a sleep disorder and low mean means there is less sleep disorders (Table 1). Overall, Trouble in sleeping was reported by $36 \%$ of elementary schools children.

The findings of the study related to students' mental health showed that the mean and standard deviation of mental health was $72.08 \pm 15.37$. The highest mean related to the conduct disorder was reported at $22.07 \pm 4.61$ and the lowest mean of the elimination disorders was reported at $48 \pm 72$. In other words, the high mean showed mental health disorder and the low mean showed a lower mental health disorder (Table 2). Overall, mental health disorders was observed in $24.5 \%$ of elementary schools children.
Table 1. The mean and standard deviation of the sleep habits of elementary students.

\begin{tabular}{lcccc}
\hline Sleep habits & Mean & SD $^{*}$ & Min & Max \\
\hline Sleep time & 17.50 & 3.87 & 12.00 & 36.00 \\
\hline Sleep behaviors & 26.87 & 4.75 & 18.00 & 46.00 \\
\hline Night awakening & 4.35 & 1.48 & 3.00 & 9.00 \\
\hline Morning awakening & 10.20 & 2.65 & 7.00 & 19.00 \\
\hline Daytime sleepiness & 5.77 & 1.77 & 4.00 & 12.00 \\
\hline Total & 64.72 & 9.33 & 44.00 & 107.00 \\
\hline standard deviation* & & & &
\end{tabular}

Table 2. Mean and standard deviation of mental health in elementary students.

\begin{tabular}{lcc}
\hline Mental health & Mean & SD \\
\hline Attention deficit/ hyper activity disorder & 10.39 & 7.17 \\
\hline Oppositional defiant disorder & 12.13 & 2.95 \\
\hline Conduct disorder & 22.07 & 4.61 \\
\hline Generalized anxiety disorder & 3.72 & 2.80 \\
\hline Anxiety and tic disorders & 2.71 & 2.99 \\
\hline Psychiatric disorders & 2.21 & 2.36 \\
\hline Mood disorders & 4.51 & 2.94 \\
\hline Pervasive developmental disorders & 6.50 & 5.31 \\
\hline Social phobia & 2.76 & 1.77 \\
\hline Separation anxiety disorder & 4.54 & 4.24 \\
\hline Elimination disorders & .48 & .72 \\
\hline Total & 72.08 & 15.37 \\
\hline
\end{tabular}

Table 3 shows that there were significant relationships between sleep habits and mental health (Spearman's rank correlation coefficient, $\mathrm{r}=0.48, p<0.001)$. The results indicated that Pearson's coefficient of sleep habits with A, oppositional defiant disorder, and conduct disorder were $\mathrm{r}=0.17, \mathrm{r}=0.61$ and $\mathrm{r}=$ 0.72 , respectively $(p<0.001)$.

The regression analysis showed sleep habits had significant associations with the mental health score. In other words, improper sleep habits were associated with higher scores of illness symptoms of mental health that are indicative of poor mental health (table 4).

\section{DISCUSSION}

The first part of the objective targeted by this study was to identify the sleep habits among Iranian elementary school children. According to the results of this study, trouble in sleeping was reported by $36 \%$ of elementary schools children. Which shows high prevalence of sleep problems. Sleep problems are frequent in children ${ }^{15-17}$. Ipsiroglu et al. surveyed school children 11 to 15 years; $12 \%$ of the children reported sleep problems every night, $76 \%$ reported occasional sleep problems, and $12 \%$ had no sleep problems ${ }^{15}$. Fricke-Oerkermann et al (2007) reported in self- and parental reports, about $30 \%-40 \%$ of the children of the longitudinal sample had problems falling asleep at the first assessment ${ }^{16}$. In the study of Liu et al., $16 \%$ of the parents of the U.S. sample reported that their children aged 4 to 11 years "sometimes" and 5\% "usually" have difficulties falling asleep ${ }^{17}$. 
Table 3. Relationship between sleep habits and mental health of elementary students.

\begin{tabular}{|c|c|c|c|}
\hline \multicolumn{4}{|c|}{ Sleep habits } \\
\hline Mental health & $\mathrm{N}$ & $\mathrm{r}$ & $p$-value \\
\hline Attention deficit/ hyper activity disorder & 240 & 0.17 & 0.008 \\
\hline Oppositional defiant disorder & 240 & 0.61 & 0.001 \\
\hline Conduct disorder & 240 & 0.72 & 0.001 \\
\hline Generalized anxiety disorder & 240 & -0.02 & 0.76 \\
\hline Anxiety and tic disorders & 240 & -0.04 & 0.49 \\
\hline Psychiatric disorders & 240 & 0.06 & 0.33 \\
\hline Mood disorders & 240 & 0.07 & 0.23 \\
\hline Pervasive developmental disorders & 240 & 0.08 & 0.16 \\
\hline Social phobia & 240 & 0.11 & 0.07 \\
\hline Separation anxiety disorder & 240 & 0.05 & 0.40 \\
\hline Elimination disorders & 240 & 0.07 & 0.26 \\
\hline Mental health & 240 & 0.48 & 0.001 \\
\hline
\end{tabular}

Table 4. Relationship between sleep habits and mental health of elementary student with linear regression.

\begin{tabular}{lccc}
\hline Variables & $\mathrm{r}$ & $\mathrm{SE}$ & $p$-value \\
\hline y-intercept & 19.86 & 6.151 & 0.001 \\
\hline Sleep habit's & 0.80 & 0.09 & $<0.001$ \\
\hline * Standard Error & & &
\end{tabular}

Sleep disorders may be seen between $20 \%$ and $30 \%$ of children which includes sleep problems (dyssomnias) or other poor phenomena in sleeping (parasomnias) such as walking while sleeping. But most sleep problems are neglected in the children. Sleep is needed for the children's physical and mental health. Unfortunately, recent studies show that the lack of sleep in children is increasing because of the tendency of children to wake up at night. School-age children need more sleep than teenagers and adults, and 10 to 11 hours of night sleep is recommended for these children. Today, most children do not observe this recommended time, which can lead to a wide range of physical and mental results ${ }^{18}$.

Several studies have reported sleep disorders in children, including Hawkins et al. (2016), in a cross-sectional study done on American children, it is mentioned that $23-36 \%$ of children aged 6-9 years, $30-41 \%$ of children $13-10$ years and $41-49 \%$ of children aged 14-17 years had sleep disorders that indicated wide sleep disorders in the studied sample ${ }^{19}$. In a study on school-age children in Japan in 2013, Iwadare et al. expressed the mean of disorder in their sleep habits of $40.0 \pm 6.5$ and the most common sleep habits disorders related to sleep behavior ${ }^{20}$.

In a study by van Listenburg et al. (2010) $)^{21}$ in the Netherlands, the average disorder in the children sleeping habits was $40.50 \pm 0.59$ and the most common disorder was related to daily sleepiness habits (1. In Iran, the results of Ozgoli et al. (2016) showed that $63.25 \%$ of children had moderate to severe sleep disorders, $64.9 \%$ had disorder in the morning awakening and $28.9 \%$ had disorder in sleep behavior ${ }^{22}$.
Khazaie et al. (2013) mentioned sleep disorder and especially sleep resistance of $20.5 \%$ as the most inappropriate children's sleep habits ${ }^{23}$. Also, Mohammadi et al. (2007) in a research study on 215 children in Tehran, noted the most common disorder in children's sleep habits was a disorder in children sleeping behavior $(56.44 \%)^{24}$. However, this difference can be partly due to the structural differences in the communities, such as cultural and social factors influential on children aged between 7 and 12, which may affect other aspects of their lives, especially their sleep. Our opinion is that these differences can be mainly due to the difference in the type of instrument used to measure child sleep disorders.

The second part of the objective was to determine of mental health status of elementary school children, the results showed that the mean and standard deviation of students' mental health was $72.08 \pm 15.37$. The most disorders in dimension was conduct disorder at $22.07 \pm 4.61$ and the least disturbance in dimension was elimination disorders at $0.48 \pm 0.72$.

Mental health disorders can affect the various aspects of the child's life as well as his or her mental and physical growth in the future. $10-20 \%$ of children and teenagers around the world are involved with mental health disorders, which according to its great importance, neglecting it, is very serious ${ }^{25}$. It is expected that by 2020, 15 percent of the world's diseases burden is allocated to mental illnesses ${ }^{26}$.

Several studies have reported mental disorders in children. In a review study done by Polanczyk and colleagues, the prevalence of mental disorders in children and teenagers is $13.4 \%$ on average ${ }^{27}$. Eisenberg et al. (2013), in a study done in the United States, it is stated that $32 \%$ of students had at least one mental disorder ${ }^{28}$. In another study, Zivin et al. (2009) stated that more than $50 \%$ of students had at least one mental health disorder, most of which were related to depression ${ }^{29}$. It is important to note that these differences could be related to culture, social-environmental variables, setting, method of studies and the type of instrument used to measure child mental health.

In a study aiming at determining the prevalence and treatment of mental disorders in American children, low attention and hyperactivity were the most commonly reported disorders among children ${ }^{30}$. In Netherlands, de Graaf et al. (2012) stated the most common mental health disorders among children in dimension of mood disorders and general anxiety ${ }^{31}$. Differences in mental health disorders in different studies can be because of the use of different tools and age groups in the studies.

In general, the results of this study showed that there was a significant correlation between sleep habits and students' mental health $(p<0.001)$. Several studies have reported the relation between children sleep habit and mental health. Such as Ivanenko et al. which reported that children with sleep disorders are highly at risk of mental health disorders such as anxiety $(85 \%)$, depression (89\%), and academic failure ${ }^{32}$.

Sleep problems are known to have complex bidirectional relationships with childhood psychiatric disorders. Biggs et al. reported that inconsistent sleep schedules significantly increased 
the risk for behavioral difficulties according to SDQ scores in school-aged children ${ }^{33}$. Wu et al. also reported that preschool children with short nighttime sleep duration were significantly more likely to have behavioral problems than those with longer sleep duration ${ }^{34}$. Matamura et al. reported that a late bedtime and short sleep duration could predict subsequent development of depression and anxiety, including suicidal or self-injury risk ${ }^{35}$. Similar to previous studies, our study also showed that children aged 6-12 years with sleep problems had a high risk of mental health problems.

Our findings are consistent with previous studies indicating that sleep problems was associated with significantly higher mental disorders. Results from several investigations reveal that even modest amounts of sleep restriction result in subsequent problems with emotion regulation, mood and attention $^{30-34}$. Understanding the risk for sleep problems and the mental health relationship is important to informing clinical practice and improving health-related quality of life in elementary school children.

In summary, sleep disorders are very common in children with mental disorders and the diagnosis and management of children sleep disorders can be effective as a significant step in improving the result of the treatment and preventing recurrence of mental illness.

\section{Limitations}

1. Our study has been performed as a cross-sectional study that it is suggested that this study be done longitudinally.

2. In our study, we used a questionnaire filled with parent which would be better to use a specific questionnaire for teachers and students.

3. This study was done in a city, which may have more reliable results if it is done in a larger community.

\section{CONCLUSION}

Sleep problems in elementary school children are a frequent and not always transient phenomenon. Children's sleep problems affects their physical and mental health. Childhood plays an important role in creating proper sleep habits, which we can diagnose many improper behaviors early and on time through proper interventions and so prevent development and occurrence of complications and mental and physical problems. Our findings showed some differences in sleep habits of children in Nahavand City / Iran compared to other communities. Sleep should be considered an important factor in the health of children but it could be influenced by cultural differences and school times in other areas. Based on the results of this study, it is suggested that screening studies for children of different ages be done in order to study their sleep problems and assess behavioral disorders and perform educational programs to improve the health of children in the area of sleep health in schools that cooperation and awareness of parents, teachers, students, and those who are in relation with children play an important role. In clinical practice, children and adolescents should be included in the diagnostic and therapeutic process, as many parents seem to underestimate the severity of their children's sleep problems. Sleep Sci. 2019;12(2):94-99
Sleep should be considered an important factor in the health of children but it could be influenced by cultural differences and school times in other areas. Based on the results of this study, it is suggested that screening studies for children of different ages be done in order to study their sleep problems and assess behavioral disorders and perform educational programs to improve the health of children in the area of sleep health in schools that cooperation and awareness of parents, teachers, students, and those who are in relation with children play an important role. In clinical practice, children and adolescents should be included in the diagnostic and therapeutic process, as many parents seem to underestimate the severity of their children's sleep problems.

Over all, as our empirical base expands, we should seek to disseminate the knowledge gained in effort to arm parents and frontline practitioners with tools to screen for potential problems and strategies to optimize sleep. Such efforts may go a long way toward minimizing long term dysfunction and improving the quality of lives and mental health of countless children and their families.

This study was prepared as part fulfillment for the Degree of MSc in Pediatric Nursing and was supported by Hamadan University of Medical sciences in Iran under Grant number: 9512037374. The authors gratefully acknowledge that the financial support was provided by the vice chancellor of the research and technology sector of Hamadan University of Medical Sciences.

\section{Conflict of Interest}

All authors declare that they have no conflict of interest.

\section{Funding}

This project was supported by Hamadan University of Medical sciences, Hamadan, Iran (No. 9512037374).

\section{REFERENCES}

1. Paruthi S, Brooks LJ, D’Ambrosio C, Hall WA, Kotagal S, Lloyd RM, et al. Recommended Amount of Sleep for Pediatric Populations: A Consensus Statement of the American Academy of Sleep Medicine. J Clin Sleep Med. 2016;12(6):785-6.

2. Rasch B, Born J. About sleep's role in memory. Physiol Rev. 2013;93(2):681-766.

3. Hirshkowitz M, Whiton K, Albert SM, Alessi C, Bruni O, DonCarlos L, et al. National Sleep Foundation's sleep time duration recommendations: methodology and results summary. Sleep Health. 2015;1(1):40-3.

4. Buysse DJ. Sleep health: can we define it? Does it matter? Sleep. 2014;37(1):9-17.

5. Medic G, Wille M, Hemels ME. Short- and long-term health consequences of sleep disruption. Nat Sci Sleep. 2017;9:151-61.

6. Blunden S, Kira G, Hull M, Maddison R. Does Sleep Education Change Sleep Parameters? Comparing Sleep Education Trials for Middle School Students in Australia and New Zealand. Open Sleep J. 2012;5(1):12-8.

7. Astill RG, Van der Heijden KB, Van Ijzendoorn MH, Van Someren EJ. Sleep, cognition, and behavioral problems in school-age children: a century of research meta-analyzed. Psychol Bull. 2012;138(6):1109-38.

8. Kaneita Y, Ohida T, Osaki Y, Tanihata T, Minowa M, Suzuki K, et al. Association between mental health status and sleep status among adolescents in Japan: a nationwide cross-sectional survey. J Clin Psychiatry. 2007;68(9):1426-35

9. Shamsaei F, Cheraghi F, Zamani G. Comparing Mental Health of School-Age Children with and without Epilepsy. Iran J Child Neurol. 2016;10(3):35-41.

10. Rahimi A, Ahmadpanah M, Shamsaei F, Cheraghi F, Sadeghi Bahmani D, Holsboer-Trachsler E, et al. Effect of adjuvant sleep hygiene psychoeducation and lorazepam on depression and sleep quality in patients with major depressive disorders: results from a randomized three-arm intervention. Neuropsychiatr Dis Treat. 2016;12:1507-15. 
11. Owens JA, Spirito A, McGuinn M, Nobile C. Sleep habits and sleep disturbance in elementary school-aged children. J Dev Behav Pediatr. 2000;21(1):27-36.

12. Shamsaei F, Kermanshahi SMK,Vanaki Z, Hajizadeh E, Hayatbakhsh MR. Experiences of family caregivers of patients with bipolar disorder. Asia Pac Psychiatry. 2010;2(4):201-20.

13. Jalilolghadr S, Hashemi S, Javadi M, Esmailzadehha N, Jahanihashemi $\mathrm{H}$, Afaghi A. Sleep habits of Iranian pre-school children in an urban area: Late sleeping and sleep debt in children. Sleep Biol Rhythms. 2012;10(2):154-6.

14. Gadow KD, Sprafkin J, Salisbury H, Schneider J, Loney J. Further Validity Evidence for the Teacher Version of the Child Symptom Inventory-4. Sch Psychol Q. 2004;19(1):50-71.

15. Ipsiroglu OS, Fatemi A, Werner I, Paditz E, Schwarz B. Self-reported organic and nonorganic sleep problems in schoolchildren aged 11 to 15 years in Vienna. J Adolesc Health. 2002;31(5):436-42.

16. Fricke-Oerkermann L, Plück J, Schredl M, Heinz K, Mitschke A, Wiater A, et al. Prevalence and course of sleep problems in childhood. Sleep. 2007;30(10):1371-7.

17. Liu X, Liu L, Owens JA, Kaplan DL. Sleep patterns and sleep problems among schoolchildren in the United States and China. Pediatrics. 2005;115(1 Suppl):241-9.

18. Bruni O, Novelli L. Sleep disorders in children. BMJ Clin Evid. 2010;2010. pii: 2304.

19. Hawkins SS, Takeuchi DT. Social determinants of inadequate sleep in US children and adolescents. Public Health. 2016;138:119-26.

20. Iwadare Y, Kamei Y, Oiji A, Doi Y, Usami M, Kodaira M, et al. Study of the sleep patterns, sleep habits, and sleep problems in Japanese elementary school children using the CSHQ-J. Kitasato Med J. 2013;43:31-7.

21. van Litsenburg RR, Waumans RC, van den Berg G, Gemke RJ. Sleep habits and sleep disturbances in Dutch children: a population-based study. Eur J Pediatr. 2010;169(8):1009-15.

22. Ozgoli G, Sheykhan Z, Soleimani F, Nasiri M, Mirzaie S, Kavousi F, et al. A study of effective factors on sleep disorders in 4-6 years old children in Tehran city, Iran. Qom Univ Med Sci J. 2015;9(5):50-60.

23. Khazaie T, Portaghali P, Jamali O, Khazaie S, Miri N, Sarhadi S, et al. Sleep pattern and common sleep problems of school children in Birjand. Mod Care. 2013;9(3):257-63.

24. Mohammadi M, Ghalebaghi B, Bandi MG, Amintehrani E, Khodaie $\mathrm{S}$, Shoaee S, et al. Sleep patterns and sleep problems among preschool and school-aged group children in a primary care setting. Iran J Pediatr. 2007;17(3):213-21.
25. Kieling C, Baker-Henningham H, Belfer M, Conti G, Ertem I, Omigbodun $\mathrm{O}$, et al. Child and adolescent mental health worldwide: evidence for action. Lancet. 2011;378(9801):1515-25.

26. Biddle SJ, Asare M. Physical activity and mental health in children and adolescents: a review of reviews. Br J Sports Med. 2011;45(11):886-95.

27. Polanczyk GV, Salum GA, Sugaya LS, Caye A, Rohde LA. Annual Research Review: A metaanalysis of the worldwide prevalence of mental disorders in children and adolescents. J Child Psychol Psychiatry. 2015;56(3):345-65.

28. Eisenberg D, Hunt J, Speer N. Mental health in American colleges and universities: variation across student subgroups and across campuses. J Nerv Ment Dis. 2013;201(1):60-7.

29. Zivin K, Eisenberg D, Gollust SE, Golberstein E. Persistence of mental health problems and needs in a college student population. J Affect Disord. 2009;117(3):180-5.

30. Merikangas KR, He JP, Burstein M, Swanson SA, Avenevoli S, Cui L, et al. Lifetime prevalence of mental disorders in US adolescents: results from the National Comorbidity Survey Replication-Adolescent Supplement (NCS-A). J Am Acad Child Adolesc Psychiatry. 2010;49(10):980-9.

31. de Graaf R, ten Have M, van Gool C, van Dorsselaer S. Prevalence of mental disorders and trends from 1996 to 2009. Results from the Netherlands Mental Health Survey and Incidence Study-2. Soc Psychiatry Psychiatr Epidemiol. 2012;47(2):203-13.

32. Ivanenko A, Crabtree VM, Obrien LM, Gozal D. Sleep complaints and psychiatric symptoms in children evaluated at a pediatric mental health clinic. J Clin Sleep Med. 2006;2(1):42-8.

33. Biggs SN, Lushington K, van den Heuvel CJ, Martin AJ, Kennedy JD. Inconsistent sleep schedules and daytime behavioral difficulties in schoolaged children. Sleep Med. 2011;12(8):780-6.

34. Wu X, Tao S, Rutayisire E, Chen Y, Huang K, Tao F. The relationship between screen time, nighttime sleep duration, and behavioural problems in preschool children in China. Eur Child Adolesc Psychiatry. 2017;26(5):541-8.

35. Matamura M, Tochigi M, Usami S, Yonehara H, Fukushima M, Nishida A, et al. Associations between sleep habits and mental health status and suicidality in a longitudinal survey of monozygotic twin adolescents. J Sleep Res. 2014;23(3):290-4. 